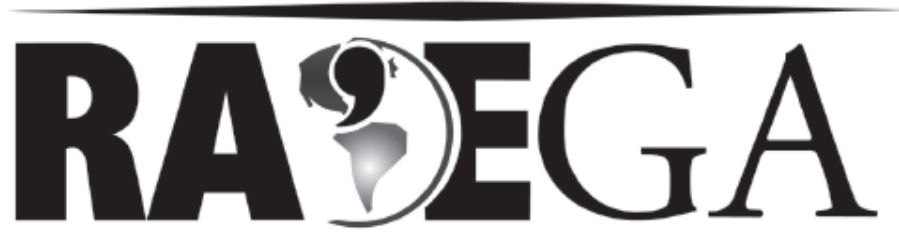

O ESPAÇO GEOGRÁFICO EM ANÁLISE

\title{
GEOGRAFIA E REPRESENTAÇÃO NA AMAZÔNIA MISTERIOSA DE GASTÃO CRULS: DA MONOCROMIA À MONOTONIA, DO FANTÁSTICO AO MISTERIOSO
}

\section{GEOGRAPHY AND REPRESENTATION OF THE MYSTERIOUS AMAZON OF GASTON CRULS: FROM THE MONOCHROME TO THE MONOTONY, FROM THE FANTASTIC TO THE MYSTERIOUS}

\author{
Susane Patricia Melo de LIMA $^{1}$ \\ Waldemir Rodrigues COSTA JÚNIOR ${ }^{2}$
}

\section{RESUMO}

A Amazônia tem sido foco de estudos por diversos autores, e estes, têm demonstrado como esse espaço geográfico pode adquirir representações a medida que se pode pensar sobre ele, individual ou coletivamente. Desde Inferno Verde, ao Paraíso Perdido, Do seu Complexo [...] à sua Invenção [...] estão presentes a valoração de cada indivíduo/autor, que sobrepõem em seus escritos como a Amazônia se traduz. Este artigo tem como principal abordagem a obra de Gastão Cruls - A Amazônia Misteriosa - que alude uma Amazônia como um contínuo mundo de mistérios, rica em cenários, e acima de tudo a consideração de aspectos que fizeram parte da vida do próprio autor e que se imbricam na obra demonstrando que as representações aproximam-se do mundo vivido de cada indivíduo.

Palavras-chave: Geografia; Representação; Amazônia; Gastão Cruls

\footnotetext{
${ }^{1}$ Universidade Federal do Amazonas. Mestranda do Programa de Pós-Graduação em Geografia/ PPGGEOG. susipatricia@gmail.com

2 Universidade Federal do Amazonas. Mestrando do Programa de Pós-Graduação em Geografia/ PPGGEOG. junior.wrc@gmail.com
} 


\section{ABSTRACT}

The Amazon has been the focus of studies by various authors, and these have shown how this geographic area can acquire the representations as they may think about it, individually or collectively. From Green Hell to Lost Paradise, from its complex [...] to its invention [...] are present in the valuation of each individual / author, which overlap in their writings such as the Amazon is translated. This article has its main approach in the work of Gaston Cruls - The Mysterious Amazon - which alludes to an Amazon as a continuous world of mystery, rich in scenery, and above all, the consideration of aspects that were part of the author's own life and that overlap in the work showing that representations come closer to the lived world of the individual.

KeyWords: Geography; Representation; Amazon; Gaston Cruls

\section{INTRODUÇÃO}

Seria que me atraísse a miragem do desconhecido, nesta Amazônia fantástica e misteriosa em que cada imaginação prefigura o Eldorado e todo indivíduo se julga um novo Juan Martinez a caminho de Manoa?

Gastão Cruls, 1957, p. 47.

Em meio acadêmico é possível constatar diversas formas de manifestação de pensamentos a respeito da Amazônia. As representações estão presentes nas mais diversas obras, que aludem desde seus aspectos naturais, até aos aspectos humanos através dos tipos humanos, ou mesmo pelos aspectos espaciais, como distância, extensão, e o outrora chamado "vazio demográfico".

Bueno (2008, p. 77) afirma que somente em mencionar-se a palavra Amazônia, uma série de informações, imagens e opiniões sobre este espaço, surgem. E este conjunto de elementos designará a representação sobre ele, que é socialmente elaborada e depois partilhada.

De Inferno Verde ao Paraíso Perdido, do Complexo da Amazônia à Invenção da Amazônia, de Pulmão Verde ao Eldorado e à Amazônia Misteriosa, pode-se observar a subjetividade imbricada nas ideias e pensamentos de autores que de uma forma ou de outra atribuíram significados 
ou valorações próprios à Amazônia, seja na personificação de um colonizador, de um poeta, de um dramaturgo, de um cientista ou viajante.

A obra de Gastão Cruls (1957), A Amazônia Misteriosa, aqui trabalhada, figura entre as literaturas que retratam a Amazônia, e sendo uma ficção, alude o misterioso, o fantástico, o imaginário ${ }^{3}$, o lúdico, além da capacidade criativa do autor em elucidar aspectos relacionados à região com tanta acurácia, desde topônimos que expressam regionalismos até os aspectos relacionados à fauna, à flora e à geografia física. A menção a outros autores que escreveram sobre a Amazônia que viram indica o nível de leitura em que o autor se debruçou a fim de retratar tais aspectos de maneira mais próxima possível do real, apesar de se tratar, como supracitado, de uma ficção. Além da ficção a obra está carregada de representações na perspectiva do próprio Cruls, o que remete ao fato de que até as leituras, pelo que podem ou não persuadirem um leitor, são representações que surgem ou que emanam da partir do outro e podem ser resignificadas pelo leitor.

A obra aparece com uma representação dominante, privilegiando dois níveis de representação, o primeiro deles, o exógeno, através das falas dos agentes externos, seus personagens não-autóctones; e o endógeno, através dos personagens autóctones, aqueles que em nada duvidam dos mistérios da região, mas que ao mesmo tempo conhecem tão bem o seu lugar que não teme sua complexidade. Neste caso, a dualidade existente na literatura parece se refletir na obra de Cruls, assim como o inferno/paraíso, o conhecido/desconhecido, o real/imaginário.

As representações geográficas apontam para a relação entre o espaço e sociedade, pois é esta sociedade que evidenciará a construção de seus pensamentos em relação ao meio em que vive. Especificamente em relação à obra de Gastão Cruls (1957), mesmo se tratando de uma obra de fiç̧ão, ele reflete seus conceitos, suas ideias, e imagens que possui da Amazônia, pelo

\footnotetext{
${ }^{3}$ Conforme Gomes (2008, p. 197) "quando utilizamos a palavra imaginário, estamos incluindo os conceitos e ideias que organizam nossas formas de pensar, apreciar e compreender objetos e fenômenos, e nessa organização os ingredientes fundamentais são o raciocínio e a lógica. Portanto, acreditamos que a racionalidade está presente no imaginário e é ela, aliás, que permite, autoriza e legitima a interpretação que fazemos".
} 
que partilha seu imaginário através de um livro que trata esta Amazônia como um grande mistério, passível de medo e grandes aventuras.

\section{NORTEANDO O LEITOR NO CONTEXTO DA OBRA: O ROMANCE, A FICÇÃO EM SI}

Assim como as representações estão sempre relacionadas a objetos e fenômenos e, estes últimos, por sua vez, podendo ser imaginários, expressos pelas narrativas lendárias, mitos de origem, utopia, ou mesmo a recomposição irrealista de elementos do real (DEBARBIEUX, 1998), a obra de Cruls também está imbuída de representações a respeito da Amazônia diretamente ligadas ao imaginário, principalmente o local, ou seja, ao escrever tal romance, Cruls não havendo estado na região, descreve-a através de uma relação estabelecida com o mundo que o cerca, principalmente através da sua leitura, leituras estas em obras que retrataram sobre a Amazônia em seus aspectos, naturais e culturais. Logo, tem-se que o conhecimento evidenciado na obra está diretamente ligado às obras que o autor menciona ao longo do livro, através da menção aos nomes de viajantes, cronistas ou mesmo cientistas/obras que estiveram na região antes dele, tais como, Bates; Byron com sua Oração à Natureza; Spruce; Rondon; padre João Daniel; Orellana; a História Geral das Índias de Lopez de Gomara; Humboldt, o geógrafo naturalista; Gonçalo Pizarro; Cristobal de Acuña; La Condamine; entre tantos autores e obras retratados no romance.

Gastão vem à Amazônia somente em 1928 acompanhando o General Rondon quando tem a intenção escrever uma Amazônia agora vista por ele próprio: "A Amazônia que eu vi”, (SILVA, 2008) evidenciando que em obras anteriores, seus escritos pautam-se, na verdade, naquilo que outras pessoas viram, e puderam passar enquanto representação individual, propondo significados à imagem pessoal que Cruls fazia em relação a Amazônia por ele concebida.

O enredo do romance fora inclusive influenciado pela profissão de Cruls que, sendo médico, aproxima a sua obra à obra, $A$ ilha do Dr. Moreau, de Herbert George Wells, que a partir da criação de seres monstruosos em uma 
ilha tropical, é condenado pelo uso da vivissecção ${ }^{4}$ e nesta ilha se refugia para colocar em prática seus intentos. Obstinado pela ideia de transformar animais em homens e vice-versa através de cirurgias, Wells, critica a maneira como o imperialismo britânico e a elite poderosa tratava seus habitantes, além de apontar como a ciência pode se constituir um instrumento de manipulação, controle e opressão do ser humano.

A relação do autor com a obra se expressa principalmente quando Cruls faz menção constante à sua própria vida, fato bem explícito na obra, através de fragmentos como:

Contei-lhe, então, que logo depois de formado tinha ido em viagem de estudos à Europa e havia praticado por quase dois anos nos hospitais de Berlim.

- Ah! Então o senhor é médico? Inquiriu, sem poder conter sua surpresa.

- Sim, ou melhor, fui, porque agora ando totalmente afastado da profissão. (CRULS, 1957, p. 71).

A indicação deste diálogo com o doutor Hartmann demonstra um fato específico da vida do próprio Cruls, agora enquanto autor da obra e não protagonista de uma ficção expressa através de A Amazônia Misteriosa.

Inspirado na literatura de Wells, Gastão Cruls retrata uma Amazônia que exerce fascínio, e em meio a uma linguagem onde se utiliza de lendas, costumes e descrição sucinta da paisagem natural e insere a figura de um "doutor", que além de personagem é o narrador da trama, que em uma jornada pela Amazônia leva consigo uma equipe de trabalho com destaque para a figura de Pacatuba que começa a trama ao lado do doutor e termina com ele.

Tal equipe se perde na floresta amazônica, momento em que separamse, e três deles são levados por um grupo de índios até as lendárias amazonas, entre eles o Doutor e o Pacatuba, e o terceiro morre a caminho com impaludismo ${ }^{5}$.

Já na tribo das amazonas, passam a conhecer a rotina de uma tribo composta somente por mulheres, participam de suas tradições e entram em

\footnotetext{
${ }^{4}$ A vivissecção é entendida aqui como a dissecação de um animal vivo com a intensão de proceder com estudos.

${ }^{5}$ Malária
} 
contato com seus mitos ${ }^{6}$. Ao ingerir aiquec ${ }^{7}$, o doutor é levado a uma viagem onírica, encontrando Ataualpa, último imperador inca, e descobre no meio de que povo está, quais os motivos que levaram este povo a habitar ali, e, principalmente, descobre que se trata das amazonas, índias guerreiras, mulheres que constituíram uma organização pautada na ginecocracia, onde os homens só apareciam uma vez por ano para perpetuar a espécie. Estes homens sendo seus vassalos desempenhavam o papel de proteção, principalmente contra estrangeiros à tribo das guerreiras (CRULS, 1957).

O narrador-personagem expresso na figura do doutor, mostra uma sociedade de mulheres organizadas, desenvolvidas, com alto grau de técnicas como jamais se observara em qualquer lugar da região, indicando que partiam ou se originavam de um modo diferenciado expresso no seguinte trecho, onde Ataualpa pergunta: " - De que te espantas? [...] Isto é apenas um resto de tudo o que tivemos, e mal chega para dar uma pálida ideia do que foram algumas civilizações americanas" (CRULS, 1957, p. 112).

A vivência na tribo possibilita ao doutor conhecer um cientista alemão, que apesar da proteção oferecida pelos índios conseguiu adentrar os seus domínios territoriais, e tal alemão, chamado de Jacob Hartmann e sua esposa chamada Rosina, com dois ajudantes, desenvolviam pesquisas científicas com animais e crianças recém-nascidos rejeitados pelas índias, que davam seus filhos do sexo masculino, por se tratar de uma sociedade tipicamente feminina. As experiências perpassavam pelo cruzamento de gente com macacos, animais de espécies diferentes, e tal fato choca o doutor a tal ponto, que 0 mesmo o questiona e aponta a obra A llha do Dr. Moreau onde de semelhante modo se realizava experimentos científicos com humanos:

- Ah, então o senhor já andou a correr isso tudo?

- Tudo não, mas o bastante para ficar mais que revoltado e poder julgá-lo como um novo Dr. Moreau, e da pior espécie...

Pelo seu jeito de espanto, percebi que não compreendera a minha referência.

- Dr. Moreau? Inquiriu surpreso.

\footnotetext{
${ }^{6}$ Conjunto de valores e crenças relativos a uma cultura e serve como grade fundamental de significação de imagens e discursos (BARTHES, apud GOMES, 2008, p. 196).

${ }^{7}$ Bebida forte ingerida pelas índias que através da alucinação possibilita visões de passado, presente e precisamente de futuro, possíveis perigos e ameaças futuras (CRULS, 1957).
} 
- Sim, repeti. O senhor nunca leu $A$ ilha do Dr. Moreau, de Wells? Pois é um romance muito conhecido. O Dr. Moreau era um médico que se meteu a transformar bichos em gente, ao passo que o senhor quer fazer justamente o contrário (CRULS, 1957, p. 150).

Apaixonados, Rosina, a esposa de Hartmann, e o doutor decidem fugir, pelo que Rosina morre ao ser flechada durante a perseguição, e o romance termina com o doutor chorando a morte de sua amada.

A obra de Cruls está dividida em capítulos escritos linearmente em uma estrutura quase descritiva, como um diário, onde o autor se preocupa com 0 vocabulário regional, e este vocabulário está expresso no elucidário ao final do livro, primordial para o leitores que desconhecem termos específicos da região.

Por se tratar de uma ficção e não tendo Cruls ainda estado na região, a sua obra se mostra como uma das notáveis em nível de representação e imagens da Amazônia. No item a seguir abordar-se-á a respeito de que imagens e representações se fala, e mais, o que são estas e sob quais perspectivas.

\section{A AMAZÔNIA DE CRULS: REPRESENTAÇÃO E IMAGEM}

É de uma Amazônia imbuída de significados com preponderância de imagens e representações que Cruls fala em A Amazônia Misteriosa.

As imagens são aqui entendidas como retratadas por Gomes (2008) onde a imagem pertence ao domínio da representação, são produtos quase que exclusivamente visuais, por ter este sentido (a visão) preeminência dentro da cultura ocidental. Gomes (2008) ressalta ainda que conhece a possibilidades de outros caminhos para analisar as imagens, como as imagens sonoras, degustativas ou da memória, porém, enquanto cópias de um mundo real ou realidade e sua figuração de imagens, possibilitando as representações de serem tanto melhores quanto mais próximas forem da realidade, já têm sido contestadas segundo críticas de que as representações não espelham 0 mundo, mas sim o criam (GOMES, 2008, p. 193).

Ao tratar a dualidade da realidade e suas representações, Gomes (2008) menciona que pode ser paralisante lidar com essa dualidade quando 
ocorre a crença de que as representações refletem com exatidão a realidade e, ainda, "tampouco parece ser possível avançar muito quando pensamos que o mundo das representações se constrói independentemente de qualquer referência subjacente, relativa ao mundo material e sensitivo"(GOMES, 2008, p. 193).

Para Gomes (2008)

as representações criam seus sistemas, quadros próprios, carregados das tintas de cada momento e embebidos nos contextos de cada lugar ou grupo social. As representações expressam escolhas a partir de princípios de significação que Ihes são próprios e também transitórios, ambíguos e polimorfos, ou, como gostamos de dizer atualmente, complexos. (GOMES, 2008, p. 193)

Neste sentido a indagação a respeito das representações deve se constituir primordial a fim de que não se volte para uma pretensa realidade da qual as representações se aproximam ou se afastam, como se a realidade que espelhassem fossem exatamente assim, mas ao contrário, estão nas suas significações, o que se exprime através delas (GOMES, 2008).

Em A Amazônia misteriosa a Amazônia parece ser vista como um laboratório repleto de riquezas visíveis, mas também ocultas, e por hora confunde-se o que é imagem e o que é representação. Conforme aludido por Debarbieux (1998) os dois termos parecem mesmo um problema de análise por parecerem muitas vezes intercambiáveis, sem muita precisão terminológica e nem transparência teórica.

Mas a representação de Amazônia sugerida em Cruls retoma uma natureza fascinante, misteriosa e imensa a ponto do autor retratá-la da seguinte maneira: "É preciso conhecer o que é a imensidade da Amazônia para poder avaliar a mesquinhez ridícula que assumem as cartas geográficas, quando, diante delas, procuramos refazer mentalmente algum trecho já percorrido" (CRULS, 1957, p. 18).

Neste trecho da obra é cabível evidenciar que a imagem cartográfica não é suficiente para demonstrar uma cópia do real. E esse mistério enfatizado pelo autor é demonstrado a cada incursão descrita como um lugar 
desconhecido, carregado de surpresas e em muitas vezes, associado a experiências desagradáveis.

Seguindo com a Amazônia de Cruls, outro ponto possível de ser analisado é da Amazônia vista como um mundo à parte do resto do mundo (p.13), pronta para ser explorada, estudada, bem como refletida pelos intentos do doutor Hartmann.

Uma Amazônia monótona por sua monocromia. Este ponto enfatizado por Cruls demonstra uma representação de amazônia a partir de sua natureza, da sua paisagem ou seja um aspecto mais físico associado ao visual. Sua densa floresta, rios caudalosos e imensa distância aparece na obra com nuances de crítica

[...] Mais um dia monótono e cansativo. (p.11)

[...] Hoje, pela primeira vez, dei razão a Agassiz, quando fala na "monotonia triste e enfadonha das paisagens amazônicas. [...] Nem mesmo há aqui gradação dos verdes. Uma única e mesma tinta sombria empasta toda a vegetação, das frondes altanadas às plantas mais mofinas. (p.17)

Sabe-se que há uma expressão de desgaste através do exagero na monocromia da paisagem, e isso reflete apenas o que o narrador/personagem sentia diante da visão que tinha naquele momento. E conforme alude Gomes (2008) as imagens não estão distante dos sentidos e associações, seus significados em dado momento. E no momento do personagem, distante da família e de "mais de um mês que tivemos o último vestígio do civilizado"( $p$. 13), o protagonista exprimia sua representação também a partir dos sentimentos

Como se poderá passar um dia de Natal isolado do mundo, em plena selva amazônica? Foi esta a primeira pergunta que me fiz hoje de manhã, transportando-me pelo pensamento ao lar longínquo e dominado por uma onda de saudade. E só então compreendi bem os versos do poeta: Home! Sweet Home! ( p. 18).

O sentimento de saudade e nostalgia em relação ao seu mundo vivido implicava em expressão do que naquele dado momento a Amazônia 
representava para ele: distanciamento, isolamento, mundo à parte de seu mundo, portanto, "tudo aquilo era revolto, emaranhado, inóspito [...]" (CRULS, 1957, p. 30) e contribuía para que Cruls associasse aos seus próprios sentimentos as frustrações do isolamento e, evidentemente, que isso pesaria negativamente em relação à imagem e representação de Amazônia que o narrador/personagem teria e iria expor na obra. O conteúdo crítico seria ressaltado e atribuído a qualquer lugar que representasse o mesmo distanciamento, isolamento, o que significa, que não é a Amazônia em si, revoltante, emaranhada e inóspita, mas os sentimentos do personagem em relação ao seu mundo vivido que permitiram essa visão de Amazônia.

A Amazônia das palavras diferentes, regionais, assim também é apresentada a Amazônia, e durante todo o texto o autor destaca termos regionais como igarité, paraná-mirim, arubé, caxiri, furo, igapó, entre tantos expressos no elucidário no final do livro. A representação da Amazônia a partir de seus nomes, topônimos, está imbricada em uma imagem do diferente, do outro desigual, do estranhamento, que não deixa de ser enfatizado a partir do preconceito em relação à preguiça atribuída aos homens amazônicos por tantos autores, e não fora diferente com Cruls.

Durante todo o percurso, vimos extensas roças muito bem cuidadas e de culturas diversas, onde numerosos grupos de índias trabalhavam, umas já na colheita, outras revolvendo a terra ou capinando o chão, em certos pontos corrido de regueiros e sangradouros. A graça mesmo é que não havia um único homem na labuta. (CRULS, 1957, p. 66)

Termos como silvícolas, bugres, selvagens, não civilizados, broncos, especialmente ao mencionar o fato de que Hartmann alegou fazer pesquisas sobre a afasia ${ }^{8}$ dos índios. Tais indígenas eram considerados broncos por não exercerem comunicação semelhante a do cientista. Ou seja, a linguagem, a oralidade dos autóctones é colocada em xeque pelos não-autóctones, muito semelhante ao modo como o colonizador europeu os identificou quando de sua chegada ao Brasil em época de colonização.

\footnotetext{
${ }^{8}$ Impossibilidade por lesão cerebral de expressão pela escrita ou sinais, ou ainda de fala.
} 
A Amazônia das mulheres guerreiras, do reino das amazonas, se torna o ápice da obra fazendo alusão ao movimento feminista vigente a partir de 1970 e quanto à periodicidade da obra, esta é sucintamente revelada quando o protagonista retrata o ano novo, fazendo alusão a primeira guerra mundial, implicitamente há uma relação entre os experimentos científicos e a situação de guerra vivida. A Alemanha como um país regulado pela aplicação do racionalismo, considerou Cruls, abominável juntamente com os experimentos desenvolvidos pelos médicos alemães em prisioneiros nos campos de concentração e a estrutura do Estado Nazista (SILVA, 2008).

Se toda representação pode ser considerada processo pelo qual são produzidas formas, concretas ou ideais e imagens são produtos da representação (DEBARBIEUX, 1998), toda forma de expressão de pensamentos podem ser entendidos como forma de representação.

Em A Amazônia Misteriosa tem-se como cenário a Amazônia imbricada de imagens construídas pelo autor, que se faz presente na obra como um narrador-personagem, que por vezes, trás a tona a expressão de seus próprios pensamentos, ao mesmo tempo produto e produtor das representações deste espaço geográfico. Isso porque pode-se entender o pensamento como uma das mais expressivas fontes de produção e recepção de representações e, também, como o mais expressivo componente de idealizações e imagens construídas pelos próprios indivíduos, o que permite a compreensão acerca do mundo e das coisas. De fato os pensamentos mudam de indivíduo para indivíduo, o que implica em ressaltar que a construção do mundo que cada indivíduo constrói se dá em uma perspectiva muito mais individualizada do que coletivamente, porém, o coletivo possibilita com que o pensamento individual possa ser construído.

Pode-se vislumbrar tal detalhe na obra de Cruls quando se identifica que ele a escreveu antes de ter vindo a Amazônia, e em torno de sua leitura em outras obras, ou seja, as representações de Amazônia existente em outros autores fez com que Cruls pudesse construir sua própria representação, que antes de tudo fora construída por outros e, posteriormente, reconstruída pelo próprio autor. 


\section{CENÁRIOS DE GOMES (2008) EM CRULS (1957)}

Gomes (2008, p. 200) propõe a inserção do cenário para reconectar a dimensão física às ações, ou seja, reconectar os arranjos espaciais aos comportamentos com a finalidade de interpretar significações. Para o autor é interessante, apesar dos limites, analisar imagens na geografia a partir de cenários, ou seja, "se constitui uma produtiva possibilidade de ler, trabalhar e interpretar as imagens a partir de um ponto de vista geográfico"(GOMES, 2008, p. 208).

No caso de se utilizar o conceito de cenário com esta finalidade, faz-se necessário entender o que tal autor aponta como teoria, ou mesmo como conceito. Para Gomes (2008), os cenários além de serem compostos por imagens fixas, pinturas, gravuras e fotografias passíveis de serem analisadas em seu enredo, trama, elementos que compõem a imagem, posições relativas, raciocínios que induzem, a espacialidade, e ainda, elemento ocultos que mesmo estando implícitos são presentes na trama. Os cenários também devem ser considerados a partir da vida social cotidiana, que neste caso, adotará passos para sua interpretação diferentemente de uma obra de arte, a intencionalidade, por exemplo, não é considerada, nos cenários da vida cotidiana, pois não estão imbuídos de intencionalidade mesmo, são estes frutos de um simples fluxo da vida, onde pessoas se emaranham independente de sua consciência de ação. Pessoas podem, neste sentido, serem objetos e sujeitos desta encenação (GOMES, 2008).

E nessa caracterização de cenário é possível dar ênfase no lugar e na ação, ou seja, como proposto por Gomes (2008) inicialmente, no arranjo espacial e no comportamento.

Na obra de Cruls (1957), por exemplo, há um cenário descrito, narrado e um agrupamento de imagens que são apresentadas a partir dele. Se ora temse como espacialidade a própria Amazônia, a floresta, a tribo das mulheres guerreiras perpassando do amplo espaço ao lugar como proximidade, ora há também a composição deste cenário, imbuído de vida que se desenvolvia para além da intencionalidade. Tanto nas investidas pela floresta, quanto no 
cotidiano das amazonas, quanto no momento da chegada do doutor e Pacatuba à tribo, uma série de cenários possíveis seriam passíveis de análise.

Se os arranjos espaciais estão firmemente consolidados na obra através dos lugares apresentados, pode-se destacar com ênfase a chegada dos dois (Doutor e Pacatuba) à floresta, os rios, o ambiente da tribo, as habitações bem construídas, a ênfase ao lugar e ações e comportamentos que ali se imbricam podem se constituir na posição de Gomes (2008) uma possibilidade de análise onde a ciência geográfica poderia permear.

Para o narrador/personagem, o Doutor, a vida cotidiana na tribo se apresenta como um fascínio mediante a identificação de mulheres amazonas e sua fantástica organização, elucidando aspectos do lugar e da ação enquanto cenário. Para destacar a ação há que se trazer um trecho onde é descrito a forma de organização ou como se comportam as vestais no seio da tribo:

- Olhe, vamos por aqui, disse-me o alemão, que eu quero apresentá-lo à Coia. Hoje é segunda-feira e ela dever estar no tambo, presidindo a distribuição de mantimentos.

E como se o meu olhar interrogasse:

- A Coia é a rainha das Amazonas. Ainda aqui, como entre os Filhos do Sol, há uma perfeita organização social e todos trabalham, desde as crianças até as velhas, sendo que os bens pertencem à comunidade e são irmãmente divididos, conforme as necessidades de cada um. À classe das amazonas propriamente ditas, que é constituída pelas raparigas de quinze a vinte e cinco anos, estão afetos os trabalhos mais difíceis e pesados, como a caça e a pesca e, também, o amanho da terra e o preparo das roças. Todas as raparigas guardam obrigatoriamente a virgindade durante esses dez anos e vivem sob uma disciplina férrea, obedecendo cegamente às ordens da Coia. Esta é escolhida entre suas companheiras após reiteradas provas de resistência física, agilidade e bravura, nas quais terá que sobrepujar as outras da mesma idade. O seu reino dura o espaço de cinco anos, dos vinte aos vinte e cinco, que pode entretanto ser dobrado, desde que ela aceite renovar o voto de virgindade e volte a ser vencedora em novas provas. É o caso da Coia atual, que já está no poder há quase dez anos. Este ano, porém, ela terá de perder o cetro, pois que não são permitidos mais de dois períodos de governo. As amazonas dos vinte e cinco anos em diante, destinam-se à perpetuação das espécies e começam a consorciar-se com os índios que as vêm visitar anualmente. São-lhes então, conferidos trabalhos mais leves e, além da criação das filhas, ocupam-se com serviços de tecelagem e confecção de vestuários e adornos. Às velhas são tributados outros misteres, 
como a manufatura da cerâmica e preparo dos tóxicos, no que são habilíssimas (CRULS, 1957, p. 88 e 89).

Diante do conceito de cenário em Gomes (2008) com o fim de servir para elucidar figurações espaciais e suas relações com o enredo ou trama, vêse em Cruls a expressão dada ao lugar, ou seja, a forma como se exprime a espacialidade, através do destaque dado a uma descrição tão minuciosa dos detalhes da paisagem como da floresta, dos rios, dos animais, entre outros.

No capítulo "As últimas páginas do diário" o protagonista apresenta em forma de diário, epistolarmente, a descrição diária dos atos realizados pelo grupo, bem como a paisagem que compunha o cenário, árvores, pássaros e até "grandes nuvens enfarruscadas surgiam de todos os lados e, em pouco, a luz parecia descer de um céu de chumbo. A atmosfera era tão abafante e toda a natureza, imóvel, trazia ar de susto [...]"(CRULS, 1957, p. 20). Isso remete a detalhes específicos da natureza, mas por ora, o autor perpassa pela descrição de lugares menos relacionados ao natural e muito mais associados ao cotidiano na tribo, como o tambo ${ }^{9}$, por exemplo, que se constitui uma espacialidade inerente à organização das amazonas, como as vestais se relacionavam coletivamente.

\footnotetext{
${ }^{9}$ Armazém de abastecimento
}

[...] corri todas as dependências do armazém, e não soube o que mais admirar: se a ordem que presidia ao seu arranjo, se a diversidade e profusão das mercadorias em depósito, a atestar o grau de adiantamento e operosidade daquele povo. Dir-seia um grande bazar em que houvesse de tudo, desde os gêneros alimentícios, até os pertences de vestuário e os pequenos objetos de uso doméstico. A um lado, enfileiravam-se igaçabas e cuiambucas com bebidas fermentadas, óleos vegetais, mel e manteiga de tartaruga, e, também, paneiros de farinha e grandes cestos contendo milho, favas, raízes diversas, palmitos, cocos. Mais adiante, empilhavam-se redes, esteiras, japás, aturás, e tudo o que é trançado com fibras ou varas de taquara. Depois vinha a secção de artefatos para caça e pesca, onde parei longo tempo, a examinar os muitos modelos de arcos e flechas, as curiosas zarabatanas, as zagaias de ponta de osso, os 
tacapes, murucus e tangapemas. Nada, porém, me agradou tanto como a enorme coleção de trabalhos de cerâmicas. A louça era perfeitamente polida e havia moringas e jarros de formas caprichosas e decorações bizarras, em que a habilidade do ceramista e do pintor corriam parelha, revitalizando nos apuros do gosto (CRULS, 1957, p. 90).

Descrever o tambo, como um lugar onde parte das atividades das amazonas ocorria, exprime uma espacialidade que não se resume simplesmente, à natureza e à paisagem, mas também a lugares tipicamente construídos para dar viço à trama que compõe o cenário. E para Gomes (2008) está traduzida em dimensões físicas e imateriais, a primeira relacionada ao arranjo material de objetos em dada configuração, e a segunda, relacionadas às ações.

Mencionar a dimensão espacial e a dimensão "conserva a centralidade da dimensão geográfica" e "permite a demonstração da importância na interpretação de imagens" (GOMES, 2008, p. 200).

Identificar estes aspectos na obra de Gastão Cruls indica a possibilidade de se pensar a dimensão geográfica na análise de uma estrutura narrativa considerando a vida cotidiana e seu conjunto de ações e de espacialidade.

\section{CONSIDERAÇÕES FINAIS}

A imagem e representação da Amazônia vista na obra A Amazônia Misteriosa de Gastão Cruls, permite a apreensão de uma Amazônia que vai além de sua paisagem florestal, mas que em meio a tais aspectos naturais está imbricada por um arranjo de mistério, medo, fantasia e uma Amazônia à parte de qualquer outro lugar do mundo, como se esta fosse isolada de um todo no mundo.

A construção das representações ocorre de maneira tal que estas se exprimem na dinâmica das relações sociais e também espaciais, ou seja, relação da sociedade com seu espaço.

Em relação a Amazônia existem diversas interpretações para as representações e imagens e, expressas nas mais diferentes obras que a 
retratam, quase sempre se inter-relacionando ao seu aspecto natural, e no caso específico desta, engendra-se uma Amazônia que além de misteriosa, e por vezes monótona e monocroma, é também rica em aventuras, desconhecimentos e valorações individuais que muitas vezes sobrecarrega-se de preconceitos e estranhamentos.

Assim, Cruls reflete a Amazônia que ele não viu, mas que entendeu a partir de suas leituras, que em síntese geral, influenciaram muito naquilo que ele pensou e representou sobre a ela. É certo que em termos de regionalidade, Cruls foi bem fiel, mas o lúdico por ele mencionado também elucida uma Amazônia que paradoxalmente é distante, mas próxima do imaginário que dela já se tem, ou seja, suas representações não estarão destoante do que fora refletido em A Amazônia Misteriosa, por um escritor que ora se confunde com personagem e como o próprio narrador.

\section{REFERÊNCIAS BIBLIOGRÁFICAS}

BUENO, Magali Franco. Natureza como representação da Amazônia. In. Espaço e Cultura, UERJ, Rio de Janeiro, N. 23, P. 77-86, JAN./JUN. DE 2008.

CRULS, Gastão. A Amazônia Misteriosa. Coleção Saraiva 115. São Paulo: Saraiva, 1957.

DEBARBIEUX, Bernard. As problemáticas da imagem e da representação em Geografia. In: BAILLY, Antoine (Org.). Les concepts de la Geographie humaine. 4ed.. Paris: Armand Colin, 1998. Tradução de Ricardo José Batista Nogueira.

GOMES, Paulo César da Costa. Cenários para a Geografia: sobre a espacialidade das imagens e suas representações. In: ROSENDAHL, Zeny; CORRÊA, Roberto Lobato. Espaço e Cultura: pluralidade temática. Rio de Janeiro: EdUERJ, 2008. p.187-209.

SILVA, Alexander Meireles da. O Admirável mundo novo da República Velha: O nascimento da ficção científica brasileira no século XX. Tese de Doutorado. Programa de Pós-Graduação em Ciência da Literatura da Universidade Federal do Rio de Janeiro, Ciência da Literatura (Literatura Comparada). Rio de Janeiro, 2008. 


\section{OBRAS CONSULTADAS}

BRETON, Stanilas. Cristianismo e o conceito de natureza. In: BOURG, Dominique (Org.). Os sentimentos da Natureza. Lisboa: Ed. Instituto Piaget, 1997.

DABIRÉ, Constantin Gbâané. África: o "mito" da vida em simbiose. In: BOURG, Dominique (Org.). Os sentimentos da Natureza. Lisboa: Ed. Instituto Piaget, 1997.

DAOU, Ana Maria. Tipos e aspectos do Brasil: imagens e imagem do Brasil por meio da iconografia de Percy Lau. In: ROSENDAHL, Zeny; CORREA, Roberto Lobato. Paisagem, imaginário e espaço. Rio de Janeiro: EdUERJ, 2001.

MEDDEB, Abdelwahab. O sentimento da natureza no Islão. In: BOURG, Dominique (Org.). Os sentimentos da Natureza. Lisboa: Ed. Instituto Piaget, 1997.

PERROT, Martyne; MAGOS, Isabelle. L'AUBRAC- do Haut Lieu ao Não-Lugar Turístico? In: Cahier d'Ethnologie de La France. Cahier 9, Paysage au Pluriel, 1995, p.35-48. Tradução de Regina Sader e Simone R.B. Ferreira.

PONS, Xavier. Austrália: entre o terror e a beleza. In: BOURG, Dominique (Org.). Os sentimentos da Natureza. Lisboa: Ed. Instituto Piaget, 1997. 